\title{
EL MADRID DE GALDÓS: DE LA CALLE A LA VÍA URBANA
}

\section{Germán GULLÓN}

Universidad de Ámsterdam

\section{RESUMEN}

Tras una justificación teórica de las razones que recomiendan abordar el tema de la ciudad y la novela, el trabajo comenta el cambio experimentado por la ciudad de Madrid en la segunda mitad del siglo XIX, tal y como aparece representada en la narrativa galdosiana. Se comenta con ejemplos concretos cómo el autor en los primeros libros sitúa la acción en el Madrid antiguo, en el entorno de la plaza de Santa Ana, cerca de la iglesia de San Sebastián, donde está enterrado Lope de Vega. La calle representada es todavía un lugar donde los ciudadanos se dedican a arrojar las basuras, un mero lugar de tránsito, para convertirse en sus mejores obras en una vía pública, gracias a las mejoras municipales, como el alcantarillado. Y quizás el mayor avance en cuanto al retrato galdosiano de la ciudad es cómo el autor canario la utiliza como escenario novelesco, donde ocurren sucesos diversos, como peleas, encuentros inesperados, etcétera. Podemos decir que el ambiente urbano se convierte en el verdadero escenario de la novela y el panorama urbano.

Palabras clave: Siglo XIX. Pérez Galdós. Narrativa. Madrid

\section{ABSTRACT}

After a brief theoretical discussion about the reasons that recommend the study of the topic the city and his representation in the novel, this piece goes on to comment the urban changes experienced by the city of Madrid during the second half from the XX century, as they are introduced in Galdós's narrative. The comments illustrate how in his early books we encounter the old Madrid, located in the surroundings of the Plaza de Santa Ana, next to the San Sebastian church, where Lope de Vega is buried. The street is yet a place used by the citizens as an immense garbage bin or a place to go from one location to the other. In the later books, the city is represented more and 
more as a public place, thanks in great part to many urban improvements, as public sewer. Nonetheless, the most significant change is the way the author treats public space in his best novels, as a scenery where people meet, socialize, and so on. We can say that in this second moment, the city became the stage of the novel and its urban landscape.

Key words: XIXth Century. Pérez Galdós. Narrative. Madrid

\section{LA REPRESENTACIÓN DE LA CIUDAD EN LA NOVELA}

Hablar de una ciudad cuando se comenta una obra literaria parecerá a algunos como un tratamiento aliterario de la misma, especialmente quienes piensan que el texto artístico está hecho de palabras cuya única consistencia relevante y digna de comentario es la verbal. El crítico norteamericano Harold Bloom se ha convertido en la prensa popular en la enseña de esta tendencia, gracias a su libro El canon occidental: La escuela y los libros de todas las épocas (2005), seguido por numerosos críticos quienes como el profesor de la universidad de Yale niegan a la literatura su relevancia social con una irresponsabilidad absoluta. Lo extraordinario de Galdós y su representación de la ciudad es que recoge en su obra el nosotros, pues su narrativa posee esa grandeza de las grandes mentes que saben conjugar lo sentido y pensado por la persona individual y relacionarlo con el sentido plural de una persona que vive en sociedad. La ciudad de Madrid representada por el gran autor en sus narraciones resulta, por lo tanto, el escenario natural de la vida social, que como argumentaremos pasa de ser la simple calle, escenario para la manifestación del perfil colectivo de las gentes, a la vía pública donde reconoceremos la individualidad de los personajes.

Galdós denunció la importación de ideas al por menor del extranjero y su aplicación a la situación, especialmente ideas políticas, ${ }^{1}$ y una de ellas en diversas versiones es la del arte por el arte, adoptada por la crítica española como un dogma, y que ha limitado el alcance de obras como la narrativa del autor canario. La degrada por un lado, pues cuando se la pone junto a textos modernistas se la encuentra inferior, y, por otro lado, se niega su influencia social. La crítica y la literatura ensimismadas pueden ser las apropiadas para la narrativa modernista, pero no para la realista.

La crítica y la enseñanza de la literatura han perdido por el camino de los estudios filológicos su energía creativa. Hay que corregir con urgencia el mencionado malentendido modernista: que la grandeza de un texto depende de su precisión y belleza verbal textual. Lo mejor de un libro, de un escrito,

1. Por ejemplo en el episodio nacional España trágica (1909).

Anales, 24, 2012, pp. 149-161 
proviene de su fuerza, la energía que conserva en su seno procedente de la riqueza del acto creativo, que, a su vez, se duplica cuando una persona lee atento la obra. Quizás se nos ha escapado que un escrito ha permitido al escritor permanecer concentrado, ajeno al mundo, mientras la redactaba, y que el lector igualmente centrado ha perdido la noción del aquí y del ahora mientras la leía. Ese momento, el proceso mental que supone concentrarse eleva la conciencia, permite al hombre mientras se concentra acelerar su creatividad, al escritor al redactar y profundizar en el tema que trata, mientras al lector le emite mil y una sugerencias. Es tanto el argumento o el tema de una obra, y la energía que produce. Dicho esto conviene reafirmar de nuevo que esa energía sin proyección social carece de sentido, sería un simple subidón medio erótico-estético.

En vez de proceder hacia la palabra, pensar su significado, su procedencia etimológica, el lugar que ocupa en el diccionario, los sinónimos, las posibilidades de combinación en la frase gramatical, hagamos de ésta una mera dependiente del hombre que las utiliza. Hay un camino equivocado que venimos transitando, donde el escritor parece sometido a la palabra, y el lector, esclavo de su buen uso, de su pulido para darle esplendor. Este pulido nos obliga a usar muletas, que llamamos diccionarios, gramáticas, ortografías, para proceder adelante. Además, el camino está tan transitado y trillado que resulta imposible pensar en variantes distintas.

De hecho, parte de la energía que detectamos en los mejores escritores es que recogen en sus textos, casi sin notarlo, los cambios habidos en la sociedad del lugar donde habitan. El Madrid de la segunda mitad del siglo XIX, que irá poco a poco mudando de cara y carácter, según el desarrollo económico alcanzaba progresivamente a un mayor número de ciudadanos, que exigían un espacio urbano ajustado a sus necesidades, con transportes rápidos, tranvías y trenes, higiene pública, policía, servicios sociales, una mayor oferta cultural, teatro, zarzuela, etcétera. Se produce asimismo un traslado del centro antiguo, estrecho, incómodo para el tránsito rodado, como el Madrid de los Austrias, al extrarradio, donde el naciente urbanismo, la arquitectura moderna ofrecía una vida con mayor confort y salubridad. No olvidemos que a principios del siglo XIX todavía se arrojaban a la calle, al grito de ¡agua va!, las aguas mayores, por lo que la calle era un lugar de tránsito ciertamente peligroso.

La narrativa galdosiana recoge ese cambio causado por la ampliación de la ciudad de Madrid, que ocasionará su trasformación en una importante ciudad burguesa ${ }^{2}$. El escritor canario se enamoró a primera vista de la capital de Es-

2. Al igual que Historias del Kronen (1994), de José Ángel Mañas, representará el Madrid extenso de los años ochenta del siglo XX y del XXI, de la ciudad que copia los modelos 
paña, pues ésta le enseñaba como una encantadora de serpientes su continuo cambio de piel y una sorprendente variedad de caras. De la urbe popular que se encontró a su llegada, donde la calle ofrecía una mezcla de gentes que se cruzaban en la Puerta del Sol; por ejemplo, la señorita, como su personaje Jacinta (residente de la Plaza de Pontejos), la esposa de Juanito Santa Cruz, vestida con la sobriedad del nuevo señorío convivía en el mismo espacio urbano con la mujer del pueblo, como su rival Fortunata (residente de la Cava Baja), quienes gustaban cubrirse con mantones y moverse con gracia chulesca. Galdós además captó (inventó) de manera inigualable las distintas maneras de hablar. Los señoritos, el mencionado Juanito, iban, a su vez, sustituyendo la incómoda levita por la americana, con lo que se iniciaba el gusto masculino por las prendas que se ajustaban al cuerpo. Entonces, el olor a cocido madrileño que salía de muchas puertas y portales se mezclaba con el refinamiento de la nueva cocina en el restaurante Lhardy de la Carrera de San Jerónimo, propia de una ciudad moderna, burguesa, conservadora, capaz también de albergar a una ciudadanía ilustrada, conocedora de lo que sucede en el exterior. Esa clase media que venía a sustituir el exclusivismo aristocrático con un protagonismo que extiende la base democrática y de poder político. El protagonismo de los locales urbanos y las instituciones de nueva planta, los cafés, la Universidad, la Bolsa, el Ateneo, los teatros, la Ópera, los museos, el Jardín Botánico, redefinirá los parámetros de la vida burguesa y moderna. Coincide asimismo con la extensión de Madrid hacia el barrio de Salamanca, de calles bien trazadas, amplias, bien aireadas, que mejoraban la higiene. El estudiante canario llega y habita en el centro de la ciudad, mientras el hombre que trabaja en la prensa y comienza su carrera artística se muda hacia las zonas nuevas, al propio barrio de Salamanca. Por eso, Galdós se muestra como un apto cronista del Madrid antiguo, que tan bien conoció además de por vivir en él, a través de la amistad con dos de sus mejores conocedores, Pascual Madoz, quien en 1864 le invitó a colaborar en La Nación, y Ramón de Mesonero Romanos, al tiempo que se erige como el máximo retratista del nuevo Madrid, de su ensanche. O sea, Galdós dejó atrás la imagen del Madrid costumbrista y sus majas inmortalizada por Goya en su pintura y por Mesonero Romanos en sus libros (Calvo Serraller, 1995) ${ }^{3}$.

de vivir de los ciudadanos americanos y europeos, llenos de casas individuales o dúplex de planta baja, con su jardincito y garaje.

3. Otro texto de obligada consulta es la introducción de María de los Ángeles Ayala a Eusebio Blasco, Madrid por dentro y por fuera: Guía de forasteros incautos (2008), pues ofrece un imprescindible repaso al costumbrismo madrileño. 
Cuando un escritor empieza a concebir una obra lo primero que se le ocurre es, por supuesto, el tema. Los personajes, el tiempo y el lugar donde suceden los hechos vienen a continuación. Recuerdo estas simples nociones, porque advierten sobre la importancia que tiene el espacio donde se sitúan los hechos, que en la novela moderna suele ser una ciudad. La elección debe ser cuidadosa, porque las ciudades marcan el carácter del texto. Hay urbes que imprimen carácter a las novelas, como Venecia, donde el ambiente melancólico de sus góndolas y calles estrechas suponen un adecuado escenario para el misterio. París como Nueva York han sido lugares privilegiados para situar en ellas complejas tramas novelísticas, que su dilatado entramado de calles y la multiracialidad de sus habitantes facilitan; Londres, por su parte, ha sido el lugar ideal para los argumentos detectivescos, el crimen oculto tras sus persistentes nieblas.

En lo que respecta a la novela española y su relación con la ciudad, conocemos muchos ejemplos. Nombraré arbitrariamente unos pocos. Leopoldo Alas, Clarín, inmortalizó la clerical Oviedo bajo el nombre de Vetusta; Emilia Pardo Bazán bautizó como Marineda a su Coruña natal (La tribuna, 1883); José María de Pereda dejó un inmortal retrato de Santander en Sotileza (1884). Ya en nuestro siglo, los nombres de Mercè Rodoreda, Eduardo Mendoza, Ildefonso Falcones, y Carlos Ruiz Zafón, entre otros muchos, han puesto a Barcelona en el mapa mundial con La plaza del diamante (1962), La ciudad de los prodigios (1986), La catedral del mar (2006) y La sombra del viento (2002) respectivamente. La colmena (1951) de Camilo José Cela, y Tiempo de silencio (1962), de Martín Santos, tienen también a Madrid por escenario, en una época cuando la capital podía tomarse como el ejemplo de la ramplonería nacional de la posguerra. No deja de resultar curioso, que uno de los autores que maldijeron el costumbrismo en general y el galdosiano en particular, Juan Benet (1927-1993) fuera el autor de un estupendo libro guía de la ciudad la capital inglesa, Londres victoriano. Lo menciono porque revela una tentación en la que han caído muchos intelectuales españoles, la de presentar los lugares en los que ellos se sienten a gusto, muy superiores a los espacios donde viven, en su caso la ciudad de Madrid.

\section{LOS DOS MADRID DE GALDÓS}

Galdós residió en tres ciudades: Las Palmas de Gran Canaria, Madrid y Santander. Siendo la capital de España la que aparece continuamente como escenario de sus obras, desde La desheredada (1881), pasando por El amigo Manso (1882), El doctor Centeno (1883), Tormento (1884), La de Bringas (1884), Lo prohibido (1885), Fortunata y Jacinta (1886-1887), Miau (1888), Tristana 
(1892), y varias más ${ }^{4}$ Santander aparece menos, pero también lo encontramos en el episodio nacional Amadeo I (1910), y es bien sabido que construyó una casa en la capital cántabra, el chalet bautizado «San Quintín». Las Palmas asoma principalmente en sus escritos de juventud. Muchos lectores y críticos hemos aprendido en sus páginas a conocer el Madrid antiguo, popular, la capital de España, el balcón desde el que Galdós tomaba el pulso a la vida nacional, que ayer como hoy era bastante agitada.

Sin embargo, el malicioso Ramón María del Valle-Inclán (1866-1936), irritado por la falta de ayuda que le prestaba don Benito para llevar sus obras al escenario, el que supuestamente se negó a hablar a los hermanos Álvarez Quintero en su favor, utilizó la boca hartera de un personaje poco recomendable, Dorio de Gádez en Luces de bohemia, para denominarlo: «Don Benito el garbancero». Sólo la soberbia de un narcisista como el escritor gallego podía denominar así la tarea de un escritor de la talla del autor de los Episodios nacionales, el hombre que diseñó con firmeza los contornos de la España decimonónica en sus páginas. Expresaba a su vez el desdén por el Madrid popular que tantas páginas galdosianas inspiró, en cuyos rincones castizos, sin duda, olía a diario al plato principal de la cocina madrileña. Valle-Inclán gustaba de pasearse por el Madrid más noble de la calle de Alcalá, cuyas anchas aceras eran un buen escenario para el despliegue de su persona, embozada en su capa con vueltas rojas. ${ }^{5}$ Galdós fue un testigo de excepción de una ciudad donde predominaban los conventos, las iglesias y los palacios de los nombres, junto a las dependencias gubernamentales, todo ello con enorme barrio popular, en una ciudad donde la clase media, sus nuevas viviendas, extendiéndose por Chamberí primero y luego por el barrio de Salamanca iban ganando terreno. Las puertas de Toledo o de Alcalá fueron pronto desbordadas, las murallas derribadas, y la ciudad corrió a devorar sus alrededores.

La ciudad de Madrid para Galdós era una especie de ser vivo, que crecía, conservando su cara antigua, la popular, los aledaños de la calle de Toledo, donde situará la residencia y el trabajo de numerosos personajes, y donde la historia enseñaba que habían vivido escritores tan singulares como Lope de Vega y Miguel de Cervantes, en los aledaños de la plaza de Santa Ana.

El primer viaje de Galdós de Las Palmas a Madrid lo efectuó por medio del barco, el tren y la diligencia. Llegó al puerto de Cádiz en un vapor, de allí

4. Miguel García-Posada (2008) presenta muy bien con ilustraciones el Madrid que aparece en diversas novelas del autor canario.

5. Para honra de Valle, su figura se redime en parte, gracias a la soberbia serie de novelas dedicadas a la guerra carlista: Los cruzados de la Causa (1908), El resplandor de la hoguera (1909) y Gerifaltes de antaño (1909). 
fue en tren a Sevilla y Córdoba, donde tuvo que tomar una diligencia parte del camino, porque la línea del ferrocarril todavía no estaba terminada. Llegó a una ciudad que desde la primera mitad del siglo se había convertido en la capital política del reino, y donde la gente había tomado la calle. La vida en la calle se había convertido en uno de los fenómenos urbanos más destacados de su tiempo, y de lo que él ofrecerá un testimonio verídico en sus obras.

La invasión napoleónica fue decisiva para el inicio de esa preponderancia de la ciudad del oso y del madroño en la vida nacional. El dos de mayo de 1808 lanzó a la población a la calle a defenderla contra el ejército francés, ${ }^{6}$ consiguiendo una de las victorias más importantes de la era moderna, pues lograron detener, y en los años siguientes, derrotar al ejército más temido de su tiempo. La calle entonces, y hasta la primavera árabe del presente, se convertirá en la propiedad de la gente, que de un momento a otro puede convertirse en el escenario del cambio político. Por eso, cuando Galdós llega a Madrid, y se hospeda en la calle de las Fuentes 3, está a un paso del gran escenario nacional, a unos cien metros. Galdós de hecho será un espectador de diversas acciones populares, la sublevación del cuartel de artillería de San Gil (1866), el motín contra la reina Isabel II, que anticipó la revolución de setiembre (1868). Fue un momento cuando los cambios políticos trajeron también una transformación de la idea del espacio público. El eje autoritario de los gobiernos monárquicos va a ceder parte de su influencia, pues una vez que los madrileños experimentaron el regusto de la propiedad común ya no había marcha atrás. Este fenómeno se daba por igual en el resto de Europa.

Guy de Maupassant en uno de sus cuentos más famosos, «Bola de sebo», cuyo escenario es la ciudad de Ruán, comenta la invasión de Francia por el ejercito prusiano (1870) y expresa perfectamente el nuevo espíritu ciudadano que se aprecia tanto en España como en la nación vecina, tras nuestra revolución de setiembre (1868) y la marcha del emperador Napoleón III (1870).

Al cabo de algún tiempo, una vez desaparecido el primer terror, se instauró una nueva calma. En muchas familias, el oficial prusiano [el invasor] se sentaba a comer con ellos. A veces era educado y, por cortesía, compadecía a Francia, proclamaban su repugnancia a participar en aquella guerra. Se le agradecía ese sentimiento; además, cualquier día podían necesitar su protección. Tratándole bien tal vez conseguirían tener que alimentar a algunos

6. La valentía del pueblo madrileño la contó en el episodio nacional El 19 de marzo y el dos de mayo. De hecho, estamos ante una de las grandes novelas donde la ciudad adquiere un papel de protagonista, sus calles, sus plazas, defendidas por el pueblo. «Madrid se convierte en el símbolo de la resistencia al extranjero, al expoliador. Esta cara de la capital, que ha sido borrada con los años, aparece aquí en toda su gloria.» (Gullón, 2008a: 28). 
hombres menos. ¿Y por qué ofender a alguien del que se dependía por completo? Obrar así sería más temeridad que valentía -y la temeridad ya no es un defecto de los burgueses de Ruán, como en la época de las defensas heroicas en que se hizo ilustre su ciudad (Maupassant, 2011: 45).

Esta última frase podría aplicarse perfectamente al Madrid al que llega Galdós como joven estudiante de Derecho. Las cruentas jornadas del 2 de mayo son ya historia pasada; ahora, las algaradas van dirigidas a la corona, que como mencionamos ocasionó la renuncia al trono de Isabel II, que al poco fue sustituida por Amadeo I. La ajetreada historia de España siguió sumida en el tumulto, porque enseguida el rey saboyano renunciará al trono, que trajo la proclamación de la primera República, el golpe de Pavía y la Restauración borbónica. Tan fijos estaban los españoles en sus asuntos públicos que dejaron de lado la cuestión americana, que llevaría a las demandas de independencia, al desastre del 98.

Los dos viajes de don Benito a París, en los veranos de 1867 y de 1868, acompañando a su hermano Domingo y familia, fueron cruciales para que el joven hombre entendiera la importancia de las capitales, y lo que ellas ofrecen al ciudadano (Mathieu, 2007). Allí aprende de la grandeza de una gran ciudad europea. La capital francesa a esas alturas históricas es una ciudad puramente burguesa, donde los comerciantes no tienen ya nada de revolucionarios, ni quieren saber nada del asunto. Allí conoce el triunfo de la industria y de la ciencia, la policromía, la riqueza de los colores, la nueva arquitectura, que permitía construir espacios abiertos. Casi podemos decir que Galdós conoció de primera mano como la ciudad francesa se ganaba el sobrenombre de la ciudad de la luz, cuando la reconfiguración del trazado de sus calles, llevado a cabo bajo las órdenes del barón Georges-Eugène Haussmann (1809-1891), la vieja ciudad rompía el apretado centro para construir amplias avenidas. Tan diferente a Madrid, a la España conventual y religiosa, vuelta sobre sí misma, donde los espacios estaban pensados para llevar dentro el secreto, ocultando la nuez de la verdad. París le enseñó que la democracia, la luz, la arquitectura moderna, debían reflejar la vida ciudadana moderna, de la convivencia y de la igualdad. Años después la construcción de la torre Eiffel (1889) le mostrará cómo se pueden unir los obreros y los constructores para hacer que todo se construya como se debe en los tiempos modernos, donde tan importante es el arquitecto como quienes llevan a cabo el proyecto. La ciudad de París, las exposiciones universales que allí se celebraron y a las que Galdós acudió fueron una lección inolvidable para entender los parámetros de la vida moderna, que él llevaría grabados en la retina y en su mente. 
Al volver a Madrid, donde todavía quedaban tantas iglesias y conventos, la urbe parisina le quedó grabada como un ejemplo, urbano y social. Madrid como Barcelona se irán adaptando al modelo francés, aunque a su modo y medida, lo que viene a denominarse la nueva ciudad, cuando los conventos y palacios sean trasladados al extrarradio, y como dice Francisco Calvo Serraller entonces «[se desarrollan] las posibilidades de estos terrenos y edificios para el programa edifico burgués: construcción de hospitales, cárceles, teatros, cuarteles, escuelas, facultades, museos, mercados, pasajes, plazas, calles e incluso jardines y parques.» (Calvo Serraller, 1995: 191-192).

Tras el período de estudiante, en el año 1870, Galdós se mudará al barrio Salamanca. Irá a vivir al tercer piso de una casa de la calle de Serrano, número 8, desde cuyos balcones podía ver cómo poco a poco se alzaba el edificio de la Biblioteca Nacional. Y lo aún más importante, se fue a vivir a una casa con su familia, con Magdalena Hurtado de Mendoza, viuda de su hermano Domingo, y sus hermanas Carmen y Concha. Allí redactará el famoso artículo-reseña, «Observaciones sobre la novela contemporánea en España» (Ortiz-Armengol, 2000: 125)

Cito los comentarios de Ortiz-Armengol sobre la residencia galdosiana:

[El] barrio que había comenzado a levantar el marqués de Salamanca tres décadas antes, y al que se estaba trasladando desde entonces la burguesía que deseaba vivir a la moderna, abandonando el viejo Madrid, así como la aristocracia capaz de abandonar sus viejos palacios del casco antiguo. La casa número 8 no existe ya -es una de las pocas derribadas en los pares de la calle de Serrano, entre las calles de Goya y Villanueva- y en su lugar se levantó, ya en este siglo, la pretenciosa casa «montañesa» que hoy ostenta el número 22, edificio contiguo al que hoy forma esquina con Jorge Juan.

Desde los balcones de la casa familiar podían verse las obras de construcción de la gran mole pétrea que iba a ser la Biblioteca Nacional, sede del Museo Arqueológico y dependencias del Ministerio de Fomento, obras iniciadas el año 1866 y que no concluirán sino en 1892, año del aniversario colombino (Ortiz-Armengol, 2000: 125).

\section{LA VÍA PÚBLICA}

Galdós, entonces, en su casa de la calle de Serrano, cuidado por sus hermanas y cuñada, que adoraban al benjamín de la familia, y que costearían la publicación de sus primeras incursiones en la literatura, se dedicará en cuerpo y alma al periodismo. Actividad que le desarrolló un fuerte interés por la llamada vía pública y por los acontecimientos ocurridos en ella. La diferencia con su anterior vecindad resulta enorme, y coincidirá con un cambio en las actividades del autor. La calle pasará a formar parte de sus obras, a constituirse en 
escenario no de hechos heroicos o curiosos, sino el lugar donde ocurre la vida de los personajes individuales. O dicho de otra manera, la calle, el escenario de grandes momentos épicos, como las jornadas del 2 de mayo, dejan paso a la representación de la vía pública, donde el individuo protagonizará lo que en ella ocurre.

Si la vía pública había dejado de pertenecer a los regentes y monarcas y le pertenecía ahora a la gente común, es lógico que los novelistas progresistas se interesaran por observar cómo el público, la gente, el individuo se apoderaba de ese espacio y su comportamiento en él. Simplemente piénsese, como adelanté, que cuando un ciudadano de Madrid salía a la calle tenía un nuevo sentimiento, que la vía pública era suya, y por tanto la autoridad, los guardias tenían que mostrarle un nuevo respeto, pero ese proceso de trasformación ideológica no ocurrre de un día para otro. Las autoridades eclesiásticas seguirán tratando de imponer sus costumbres en la manera en que se visten los ciudadanos hasta bien entrado el siglo XX, apoyando el cultivo del sentimentalismo romántico. Pero lo más importante es que la vía pública, donde podemos encontrar a nuestro semejante se convierte en un lugar de expresión de la individualidad, de manifestación de experiencias particulares. Uno de los mejores ejemplos lo tenemos en la pelea habida en la calle entre Juanito Santa Cruz y Maximiliano Rubín en Fortunata y Jacinta (1886-1887). Cuando el desafortunada marido descubre que su esposa se ha convertido otra vez en amante del Delfín, y por causalidad se entera de dónde se celebran los encuentros amorosos, se aposta a la puerta del edificio hasta que Juanito sale de una de las citas, donde le confronta e inicia la pelea. Así se cuenta el incidente:

La vía estaba solitaria. Pasaba muy poca gente y hacía bastante frío. El Delfín sintió aquellos pasos detrás de sí, y una misteriosa aprensión, la conciencia tal vez, le dijo de quién eran. Volvióse a unto que la temblorosa voz del otro decía:

-Oiga usted...

Parose en firme Santa Cruz, y aunque no le conocía bien. Le tuvo por quien era, sin dudar un momento.

- ¿Qué se le ofrece a usted?

-¡Canalla!... ¡Indecente! -exclamó Rubín con más fiereza en el tono que en la actitud.

No espero Santa Cruz a oír más, ni su amor propio le permitía dar explicaciones, y con un movimiento vigoroso de su brazo derecho rechazó a su antagonista. Más que bofetada fue un empujón; pero el endeble esqueleto de Rubín no pudo resistirlo; puso un pie en falso al retroceder y se cayó al suelo diciendo:

-Te voy a matar..., y a ella también.

Revolcose en tierra; se le vio un instante pataleando a gatas, diciendo entre mugidos: 
-¡Ladrón, ratero..., verás...!

Santa Cruz estuvo un rato contemplándole con calma fría del ofuscado asesino, u cuando vió que, al fin, conseguía levantarse, se fue hacia él y le cogió por el pescuezo, apretándole sañudamente, cual si quisiera ahogarle de veras... Reteniéndole contra el suelo, gritaba:

-Estúpido..., escuerzo.... ¿quieres que te patee?...

De la oprimida garganta del desdichado joven salía un gemido, estertor de asfixia. Sus ojos reventones se clavaban en su verdugo con un centelleo eléctrico de ojos de gato rabioso y moribundo. La única defensa de lo que estaba debajo era clavar sus uñas, afilándolas con el pensamiento, en los brazos, en las piernas, en todo lo que alcanzaba del vencedor, y logrando alzarse un poco, con nerviosos coraje [...] [Juanito le levantó como una pluma y le lanzó violentamente donde antes había caído. [...] (Gullón, 2008b: 663-664)

Los viandantes tratarán de ayudarle. Unos le dan la razón, varios le piensan un insensato. Alguien deniega que pueda ser una pelea por una mujer, porque Maxi es evidentemente un «marica» (Gullón, 2008b: 666). Los guardias que llegan cuando ya marchó Santa Cruz, «dos individuos de Orden Público, que viendo a Maxi en aquel estado, le recibieron muy mal. Pensaron que era un pillete, y que los golpes que había recibido le estaban muy bien merecidos... Le cogieron por el cuello de la americana con esa paternal zarpa de la justicia callejera.» (Gullón, 2008b: 666)

Escena crucial de la novela, donde el individuo, Maxi Rubín, es presentado en su absoluta debilidad corporal y de personalidad, carece de fuerza física, y ni siquiera sabe canalizar su enfado por el cauce de una actuación normal, porque todos los resortes de la persona y de la personalidad le fallan. El señorito, sin embargo, logra escapar del lance. La injusticia de la situación sirve para mostrarnos a un individuo, Maxi de una manera que nunca lo podríamos ver por dentro, ni resultaría tan creíble.

La escena resulta verosímil porque Galdós ha hecho, probablemente influido por el hábito adquirido al redactar las crónicas periodísticas, de la calle madrileña un teatro del mundo, donde las fuerzas vivas, las gentes, cada una actúa de acuerdo con su manera de ser, sus convicciones y perjuicios. Al lector le da pena el pobre Maxi, a quien se le pone voz de pito, y resulta incapaz de despertar la bondad de los viandantes, por su catadura, por su cuerpo esmirriado, por la voz de pito, en fin, porque en la vía pública el sentido de humanidad resulta bastante restringido a las apariencias. Galdós sitúa así al personaje ante un espejo que refleja su persona de mil maneras diferentes, no sólo cómo lo ven quienes le conocen.

Lo que todo esto quiere decir es que gracias a la influencia del periodismo Galdós se interesa por la vía pública, cuando ésta se ha hecho pública, a-cortesana, burguesa y que ello le lleva a descubrir la importancia de este 
escenario para conocer a la gente. Allí se manifiesta la identidad individual de cada quien, y el arco de experiencias se aumenta enormemente. La novela se convierte, gracias a esa interacción entre el espacio novelesco y el individuo, a ese nuevo equilibrio, en un nuevo teatro de la vida. El narrador tiene menos que buscar en el interior de los personajes, lo que siempre conllevaba riesgos de verosimilitud importantes, y puede explorar precisamente cómo es el individuo en su relación con el mundo y con los demás.

La escena resulta conmovedora, pero su belleza pertenece a una categoría que difícilmente podemos caracterizar de hermosa, pues tiene la belleza de una escena esperpéntica. Es la belleza provocada por el interés en conocer los detalles, en saber cómo pueden suceder estas cosas. Camino de la Casa de Socorro, el aspecto de Maxi, el ir escoltado por dos guardias, hace que le siga bastante gente, porque se interesan por saber qué ocurre. Es la belleza del espectáculo público.

Pero la escena no se queda ahí colgada como un suceso, sino que entra a formar parte de la acción principal. Por ejemplo, las consecuencias del incidente para la parte ganadora, Juanito, aparecen en una conversación habida entre Jacinta y su marido, cuando el marido al ser pillado en adulterio, de nuevo, viene con el cuento de que todo se va terminar. Jacinta escuchó el lance en sueños de su marido. Oigamos cómo:

Otra noche dijiste en sueños palabras de las que se dicen cuando un hombre se pega con otro. Yo me asusté. Fue aquella noche que entraste muy nervioso y con dolor en el brazo. Tuve que ponerte árnica. Me contaste que viniendo no sé por dónde, te salió un borracho, y tuviste que andar a trompazos con él (Gullón, 2008b: 726).

Se establece así la conexión entre el lance y la persona, en este caso de Juanito. Lo que el Delfín cuenta a su esposa es que fue un borracho que le atacó por la calle, en un intento de impersonalizar el suceso, pero los lectores sabemos que no es así. Lo curioso es que el sueño tiene repercusiones privadas, malos sueños, mientras que las de Maxi tienen una repercusión pública.

\section{BIBLIOGRAFÍA}

Ayala, María de los Ángeles, «Introducción» a Eusebio Blasco, Madrid por dentro y por fuera: guía de forasteros incautos, Madrid, Biblioteca Nueva/Universidad de Alicante, 2008.

BENET, Juan, Londres victoriano, Barcelona, Planeta, 1989.

BLOOM, Harold, El canon occidental: La escuela y los libros de todas las épocas, Barcelona, Anagrama, 2005. 
Calvo Serraller, Francisco, La imagen romántica de España. Arte y arquitectura en el siglo XIX, Madrid, Alianza, 1995.

García-PosadA, Miguel, Guía del Madrid galdosiano, Madrid, Comunidad de Madrid, 2008, (2 $2^{\text {a }}$ ed.). http://www.madrid.org/edupubli/m_biblio.htm

Gullón, Germán (ed.), Benito Pérez Galdós, El 19 de marzo y el dos de mayo, Madrid, Biblioteca Nueva, 2008a.

Gullón, Germán (ed.), Benito Pérez Galdós, Fortunata y Jacinta, Madrid, Espasa Calpe, 2008b.

MATHIEU, Caroline, Les expositions universelles à Paris: architectes réelles ou utopiques, Paris, Continents Editions, 2007.

Maupassant, Guy de, [1880] «Bola de sebo», Todas las mujeres, Madrid, Siruela, 2011.

Ortiz-Armengol, Pedro, Vida de Galdós, Barcelona, Crítica, 2000.

Fecha de recepción: 25-11-2011

Fecha de aceptación: 30-4-2012 